\title{
Insect food in space
}

\author{
R. Kok ${ }^{1 *}$ and A. van Huis ${ }^{2}$ \\ ${ }^{1}$ Bioresource Engineering, Macdonald Campus of McGill University, 21,111 Lakeshore Rd., Ste-Anne-de-Bellevue, QC \\ H9X3V9, Canada; ${ }^{2}$ Laboratory of Entomology, Wageningen University E Research, P.O. Box 16, 6700 AA Wageningen, \\ the Netherlands; robert.kok@mcgill.ca
}

(C) 2021 Wageningen Academic Publishers

OPEN ACCESS CC)(요 EDITORIAL

\begin{abstract}
The question addressed here is how to produce palatable food on long-term space flights and during extended tenancy in space colonies. That will be done in closed ecosystems that must be stable, robust, resilient, and sustainable. In these, because of their size, insects will be an obvious food choice. A number of species have been proposed, their suitability based on characteristics such as their capacity to be reared at high densities, ability to convert organic waste, a short life cycle and a high feed conversion ratio, resistance to diseases, good nutrition and organoleptic qualities as well as being safe for human consumption. A shift to insects as food will require dietary adaptation, but will also provide many opportunities for innovation.
\end{abstract}

\section{Introduction}

As Kurt Vonnegut (2005) put it poetically: 'We are here on Earth to fart around. Don't let anybody tell you any different.' He was referring therewith to the tendency of humans to retain curiosity even as they mature into adults and our proclivity to satisfy that curiosity through the exploration of what lies beyond. The questions of what might be and what could be, expressed through imagination and speculation, have always been the driving forces for our development. Accordingly, in our history science fiction in one form or another has played a crucial role as the leading edge of scientific and technological change and achievement. The artists come first in the sequence of discovery. It is they, the story tellers, the writers, the painters, the movie makers who lead us to new insights, overcome traditional barriers and open frontiers in the mind. The curtain needs to be pulled aside and the stage revealed before the play can proceed. And so, it has gone with our exploration and use of space. Most of the concepts related to space operations, travel and habitation were first proffered in fictional form as simple extrapolations of the well-known and speculation based on a rather vague understanding of what was out there. But, because of this we now have extensive communications networks relying on thousands of satellites in orbit around Earth, robots surveying Mars, sample-return missions flying to asteroids and comets, etc. We even have a tiny colony of humans living in a space station circling Earth. So, what is to come next?

\section{What to eat?}

Following literature's lead, we will soon see mining operations being installed on asteroids and other nearby astronomical bodies, zero-g space-based manufacturing of products such as semiconductors and fine chemicals, as well as the establishment of larger human colonies both on the surface of celestial bodies and as autonomous systems. Although all this has been described and pictured in considerable detail in fictional representations an interesting aspect of those is that not very much was ever said about how the people involved in these ventures are to live their daily lives and how they shall sustain themselves. Specifically, what shall they eat? How often did we see cafeteria scenes on the Enterprise? Did Captain Kirk cook his own pizza in a microwave, or did he order out? Where did the food come from anyways? These questions have, of course, equivalents in future, real situations. Despite the likelihood that most asteroid mining and space-based manufacturing will be done by robots, it is likely that some human presence will be required to carry out facility repairs and alterations, leading to the question of how personnel will be fed. And the issue of food supply is, of course, entirely crucial for space-based systems in which a population of humans will live for longer periods, perhaps their entire lives. Accordingly, the main question that is primarily addressed here is: what role could insects play as part of the human food supply in space-based systems? 


\section{Engineering closed ecosystems}

The simplest systems that contain humans as components are small capsules that travel back and forth between, e.g., Earth and Moon to explore, collect samples, etc. In this case the trip is of relatively short duration, the intensity of the gravitational field varies between 0 and $3 \mathrm{~g}$, and sufficient food can be carried along so that supply is not a problem. However, once it becomes desirable for a group of humans to live in space for a longer period, e.g. to travel to Mars and settle long-term there or to live permanently in a 'generation ship', the food supply does become an issue and in-situ food generation becomes essential. The NASA Deep Space Food Challenge is oriented to exactly that situation, first with a view to establish and maintain a base on Moon but also with a view to future missions to Mars and beyond. In this the focus is on producing a sustainable supply of palatable food on long-duration missions, which also implies the recycling of basic substances such as water, oxygen, nitrogen and carbon as well as minerals. Thus, the overall challenge will be to learn how to engineer closed ecosystems that are stable, robust, and resilient and thereby truly sustainable in the long term. As well, of course, they must be suitable for human occupation. At least initially, these will be engineered to function at or above $0.1 \mathrm{~g}$ (at its surface Moon has a gravitational field strength about one-sixth that of Earth, Mars about one-third). Because the environmental envelopes will be small it is expected that very few, if any, of the ecosystem components will be usual food animals like chickens, rabbits, etc. It is, however, possible to include smaller, but macroscopic, animals like insects that can be eaten but also fulfil several other roles such as waste processing, pollination (see Nardone et al., 2012) and recycling. They can even serve as pets and thus provide psychological comfort.

The concept of using a closed ecosystem as human lifesupport for space travel and space colonies is not new and has been discussed extensively in both popular and scientific/technical literature. The public is also quite well acquainted with this approach due to a number of popular movies in which, unfortunately, it has not always been presented in a realistic manner. In many depictions and descriptions megafauna plays a major role but normal insects (and other small life forms such as spiders, nematodes, mites, microorganisms, etc.) are hardly ever mentioned. The best-known real attempt to create a closed ecosystem containing human occupants was probably Biosphere 2 (Nelson et al., 1993). That project was again described in some detail by Nelson et al. (2010) and, in this instance, compared with similar systems created in Japan, Europe and Russia. Although thousands of insect species were intentionally included in the ecosystem of Biosphere 2 to facilitate recycling, there was no deliberate cultivation and consumption of insects (or other mini fauna) at all by the occupants. Considering prevailing attitudes at the time (it was built between 1987 and 1991 and designed before that) that is perhaps not entirely surprising although the idea of utilising insects as a food source during space travel and similar circumstances had been presented in the scientific literature well before that (Kok, 1983).

\section{Which insect species?}

Whereas Biosphere 2 and similar projects were not always considered a 'success' in terms of their scientific objectives, one very practical lesson learned was that system designers should pay close attention to the nutritional quality as well as the caloric adequacy of the human occupants' diets. As well, for both physical and mental health reasons, those diets should be as diverse as is possible under the circumstances. After all, 'variety is the spice of life' and, in the absence of more usual food animals under such circumstances, insects and their relatives can fill the gap. As concepts and the understanding of biospheric systems have been maturing over the years, so has acceptance of the idea that insects can be part of the food supply while simultaneously playing several other roles. Thus, if they are cellulolytic like termites, they will speed up the carbon cycle and constitute a high-quality and tasty food item at the same time. Kok (1983) proposed using the drugstore beetle (Stegobium paniceum) in a similar role since it can grow on a variety of cellulosic substrates and is non-flying as an adult while its larvae are mostly white and about the size of a grain of rice, thus easy to incorporate in many foods in toto. (It was suggested the reddish head parts might be camouflaged to advantage with paprika.) A factor that favours the drugstore beetle is its capacity to grow at a very low water activity, limiting the number of organisms that might compete with it for its feed. An advantage of many termites is that they can synthesise protein de novo (with the help of gut microbiota) from inorganic nitrates and even from atmospheric nitrogen (Täyasu et al., 1994; Sapountzis et al., 2016). However, because most insects able to digest cellulose/lignin substrates are relatively slow growing, several other, faster-growing species have also been suggested.

Overall, the ideal organism will have a short life cycle and a high feed conversion ratio while being resistant to diseases and parasites. As well, it should consume by-product biomass or organic waste material, yet have a high nutritional value for humans, be safe to eat and tasty to boot. And it should be amenable to being reared in high density. A rather tall order which will probably be addressed in the future through selection and breeding programs. One candidate insect that has been favoured by a number of authors is the silkworm (Bombyx mori). As a by-product of the silk industry its pupae have been consumed for many centuries, the (cultured) adult moth does not fly, and the larvae consume mulberry leaves, the foliage of a high-yielding horticultural crop that can also 
produce edible berries whose nutritional value has been highly praised (Lochynska, 2015). The incorporation of this plant/animal combination in space-bound ecosystems and the consumption of silkworm pupae as a source of animal protein has been discussed by Katayama et al. (2005), Katayama et al. (2008), Tong et al. (2011), and Yang et al. (2009). The silk fibre from the pupae can also be converted into edible protein or, as is done traditionally, it can be made into textile. The latter activity would provide for recreational and artistic opportunities and might also lead to enhancement of the aesthetic quality of the living space of the occupants. At the same time, the waste material from silkworm culture can be used as fertiliser for plants or even as feed for fish. Yamashita et al. (2009) suggested using the convolvulus hawkmoth (Agrius convolvuli) whose pupa is two or three times larger than that of the domesticated silkworm and very edible (R. Kok, personal observation). This insect does not produce a cocoon so that, as compared to the silkworm, more of the nitrogen absorbed from the plant leaves is used for the synthesis of body protein. A disadvantage of this organism, however, is that it needs to be airborne to mate which could be rather inconvenient in a limited-volume closed ecosystem. The same authors (Yamashita et al., 2009) also proposed incorporating the termite Macrotermes subhyalinus and an unspecified fly as ecosystem components. The black soldier fly (Hermetia illucens) might very well be suitable for this role due to its capacity to digest and recycle a range of organic substrates, including many waste materials and even human remains. This fly must, however, also be airborne to mate. The yellow mealworm (Tenebrio molitor) has been put forward as a human food for multi-generation spaceships by Jones (2015) while Katayama et al. (2009) assessed silkworms, flies, bees, locusts, and termites in terms of their functionality as well as their social and aesthetic value. Altogether, a wide variety of insect types have found proponents for inclusion in the human food supply in space situations but there is one rather remarkable exception: the cockroach. Whereas one might expect this most capable, resistant, resilient, and entertaining group of organisms to be first in line, it is hardly ever mentioned as a possibility. Does prejudice perhaps play a role here?

\section{Conclusions}

All in all, as we prepare to escape the confines of our home planet to colonise other celestial bodies or simply to travel and live in space, we must realise that, no matter how we decide to live there, we will need to eat. And, unless we adapt or mutate in a rather dramatic way, our food will need to be organic and be grown in a sustainable ecosystem. Thus, we will need to carry our ecological house along with us to provide for the necessities of life. And under such conditions, insects and other anthropoda may very well be a significant component of our diet. This has been discussed, for example, by Cannon and Britt (2019) who outlined what is needed to sustain a million people on Mars and by Tomita-Yokotani et al. (2009) and Yamashita et al. (2005) who examined specific agricultural requirements. Brown et al. (2021), while acknowledging the difficulties that might be associated with maintaining an aquatic environment in space, have discussed how aquatic invertebrates might be protein sources under non-Earth conditions. A slightly different approach to augmenting the food production of a life support system is to cyborg the physical infrastructure with a sophisticated artificial intelligence (Parrott, 1995, 2000). In this approach it is possible to include a very large variety of species that will contribute to the complexity of the food web, while many of the non-food species exist virtually rather than taking up room in the physical envelope. Such a system is known as an eco-cyborg.

Evidently, living in space will require us to adapt in some major ways, including our dietary norms. It will, however, also provide endless opportunity for innovation, including the development of culinary specialties based on insects and their close relatives. Even on Earth we have already dishes that provide for both nutrition and entertainment such as the hissing cockroach tapioca pancake, an obvious favourite with children. Only the imagination limits what can be done with food on Moon, Mars and in outer space. Kurt Vonnegut had a good point about our purpose on Earth. It will apply doubly in space.

\section{References}

Brown, L., Peick, J., Pickett, M., Fanara, T., Gilchrist, S., Smiley, A. and Roberson, L., 2021. Aquatic invertebrate protein sources for long-duration space travel. Life Sciences in Space Research 28: 1-10. https://doi.org/10.1016/j.1ssr.2020.10.002

Cannon, K.M. and Britt, D.T., 2019. Feeding one million people on Mars. New Space 7: 245-254. https://doi.org/10.1089/ space. 2019.0018

Jones, R.S., 2015. Space diet: daily mealworm (Tenebrio molitor) harvest on a multigenerational spaceship. Journal of Interdisciplinary Science Topics 4: 28-29. https://journals.le.ac.uk/ojs1/index.php/ jist/article/view/767/719

Katayama, N., Baba, K., Yoshimura, T., and Yamashita, M., 2009. Insects for space agriculture and sustainable foods web on Earth. In: Proceedings of the $4^{\text {th }}$ International Conference on Recent Advances in Space Technologies, 11-13 June 2009, Istanbul, Turkey, pp. 53-55. https://doi.org/10.1109/RAST.2009.5158252

Katayama, N., Ishikawa, Y., Takaoki, M., Yamashita, M., Nakayama, S., Kiguchi, K., Kok, R., Wada, H. and Mitsuhashi, J., 2008. Entomophagy: a key to space agriculture. Advances in Space Research 41:701-705. https://doi.org/10.1016/j.asr.2007.01.027

Katayama, N., Yamashita, M., Wada, H. and Mitsuhashi, J., 2005. Entomophagy as part of a space diet for habitation on Mars. The Journal of Space Technology and Science 21: 27-38. https://doi. org/10.11230/jsts.21.2_27 
Kok, R., 1983. The production of insects for human food. Canadian Institute of Food Science and Technology Journal 16: 5-18. https:// doi.org/10.1016/S0315-5463(83)72012-2

Lochynska, M., 2015. Energy and nutritional properties of the white mulberry (Morus alba L.). Journal of Agricultural Science and Technology A 5: 709-716. https://doi.org/10.17265/21616256/2015.09.001

Nardone, E., Kevan, P., Stasiak, M. and Dixon, M., 2012. Atmospheric pressure requirements of bumblebees (Bombus impatiens) as pollinators of lunar or martian greenhouse grown food. Gravitational and Space Biology Bulletin: publication of the American Society for Gravitational and Space Biology 26: 13-21.

Nelson, M., Alling, A. and Silverstone, S., 1993. Life under glass: inside story of Biosphere 2. Synergetic Press, Santa Fe, NM, USA, 272 pp.

Nelson, M., Pechurkin, N.S., Allen, J.P., Somova, L. and Gitelson, J.I., 2010. Closed ecological systems, space life support and biospherics. In: Wang, L.K., Ivanov, V., Tay, J-H. and Hung, Y-T. (eds.) Environmental Biotechnology. Handbook of Environmental Engineering 10: 517-565. Humana Press, Totowa, NJ, USA. https:// doi.org/10.1007/978-1-60327-140-0_11

Parrott, L., 1995. The EcoCyborg Project; a model of an artificial ecosystem. MSc thesis, McGill University, Montreal, Canada.

Parrott, L., 2000. Learning to engineer life: development of a generally configurable model for the simulation of artificial ecosystems. PhD thesis, McGill University, Montreal, Canada.

Sapountzis, P., de Verges, J., Rousk, K., Cilliers, M., Vorster, B.J. and Poulsen, M., 2016. Potential for nitrogen fixation in the fungusgrowing termite symbiosis. Front Microbiology 7: 1993. https:// doi.org/10.3389/fmicb.2016.01993
Täyasu, I., Sugimoto, A., Wada, E. and Abe, T., 1994. Xylophagous termites depending on atmospheric nitrogen. Naturwissenschaften 81: 229-231. https://doi.org/10.1007/BF01138550

Tomita-Yokotani, K., Anilir, S., Katayama, N., Hashimoto, H., Yamashita, M., 2009. Space agriculture for habitation on Mars and sustainable civilization on earth. In: Proceedings of the $4^{\text {th }}$ International Conference on Recent Advances in Space Technologies, 11-13 June 2009, Istanbul, Turkey, pp. 68-69. https:// doi.org/10.1109/RAST.2009.5158276

Tong, L., Yu, X. and Liu, H., 2011. Insect food for astronauts: gas exchange in silkworms fed on mulberry and lettuce and the nutritional value of these insects for human consumption during deep space flights. Bulletin of Entomological Research 101: 613-622. https://doi.org/10.1017/S0007485311000228

Vonnegut, K., 2005. A man without a country. Seven Stories Press, New York, NY, USA, 160 pp.

Yamashita, M., Hashimoto, H. and Wada, H., 2009. On-site resources availability for space agriculture on Mars. In: V. Badescu (ed.) Mars: prospective energy and material resources. Springer-Verlag, Berlin, Germany, pp. 517-542. https://doi.org/10.1007/978-3-642-036293_18

Yamashita, M., Ishikawa, Y., Nagatomo, M., Oshima, T. and Wada, H., Space Agriculture Task Force, 2005. Space agriculture for manned space exploration on Mars. The Journal of Space Technology and Science 21: 1-10. https://doi.org/10.11230/jsts.21.2_1

Yang, Y., Tang, L., Tong, L. and Liu, H., 2009. Silkworms culture as a source of protein for humans in space. Advances in Space Research 43: 1236-1242. http://dx.doi.org/10.1016/j.asr.2008.12.009 